\title{
Relationships between Social Anxiety and Mental Health Problems in Early Adolescents from Different Socioeconomic Groups: Results from a Cross-sectional Health Survey in Norway
}

\section{Berit Sofie Karlsen $^{1 *}$, Jocelyne Clench-Aas ${ }^{2}$, Betty Van Roy ${ }^{3}$ and Ruth Kjærsti Raanaas ${ }^{1}$}

${ }^{1}$ Department of Landscape Architecture and Spatial Planning, Norwegian University of Life Sciences, Norway

${ }^{2}$ Division of Mental Health, Norwegian Institute of Public Health, Norway

${ }^{3}$ Division of Mental Health, Akershus University hospital, Lørenskog, Norway

\begin{abstract}
Mental health problems in early adolescents are a public health challenge in many western communities. The aim of this study was to examine the association between social anxiety and mental health problems, related to parental socioeconomic status. Data from a cross-sectional survey among Norwegian school-children were used

$(\mathrm{N}=9707)$, targeting pupils in 5-7 grade (aged 10-13) and their parents $(\mathrm{N}=8603)$. The Strengths and Difficulties Questionnaire was used for measuring mental health problems and their impact, based on self-reported data from the children. For determining social anxiety problems, questions from Development and Well Being Assessment were used. Parent education was used as an indicator for children's socioeconomic status. Information on social anxiety problems and socioeconomic status were obtained from the parental questionnaire.

We found a strong relationship between social anxiety and mental health problems in the group representing low parental socioeconomic status $(\mathrm{OR}=2.607)$ compared with the group representing high socioeconomic status $(\mathrm{OR}=1.169)$. Examining the individual items of the measure of social anxiety, we also found that children in the low socioeconomic status group had a higher prevalence of problems performing in front of others.
\end{abstract}

Social inequality contributes to different mental health outcomes in children with social anxiety.

Keywords: Mental health problems; Strengths and Difficulties Questionnaire (SDQ); Socioeconomic status; Educational level; Selfefficacy; Social anxiety disorder; Social performance; Social interactions

\section{Introduction}

Globally, mental health problems represent 4 of the10 leading causes of disability [1]. A growing body of research indicates that the scope of these problems increase in many western countries [2]. Often these mental health disorders originate early in life $[2,3]$. Social anxiety disorder (SAD) is a chronic illness, mainly characterized by a fear of social situations, associated with embarrassment, humiliation and a negative feeling of being observed by others [4]. The problems include both fear of social interactions and situations where there is an expectation to perform [5]. This was first presented as an independent diagnosis in the Diagnostic and Statistical Manual of Mental Disorders [DSM] -III criteria [6]. Since then, research has increasingly confirmed this condition as a mental disorder.

The lifetime prevalence of SAD is estimated as somewhere between 7 and 13\% in western countries [5]. Epidemiological studies find this disorder to be the most prevalent of all anxiety disorders, and the third most common psychiatric diagnosis [7]. This condition is distinguishable from "normal" shyness by the greater severity and pervasiveness of chronic distress and impairment in different social situations [7]. The problems often start between the ages of 11-20 [8,9].

Despite knowledge as to the prevalence of SAD during the life sequence, the association between social anxiety disorder and other mental health problems are seldom studied, and even more seldom in children. However, Van Roy et al. [10], by using the Strengths and Difficulties Questionnaire (SDQ), did point out that children with significant social anxiety have problems with both internalizing and externalizing mental health problems.

Several studies confirm the impact of socioeconomic status (SES) on mental health in children and adolescence [11-14]. It is now evident that SES differences in mental distress may be partially, but not fully accounted for, by conditions of the family environment [15]. For social anxiety, on the other hand, little is known as to the role differences in SES have on the development or manifestation of social anxiety or on its association with mental health.

Over the past two decades, social determinants of health are not only linked to material benefits, but also to social patterns and structures that shape peoples chances for promoting health [16]. Whereas income is related to material resources, educational level creates differences between people in terms of access to information and benefit from knowledge [17]. Education is also mentioned as a proxy variable for economic resources, and is considered to be a good measure of socioeconomic differences in high-income countries [18]. Parental education is mentioned as a suitable indicator in studies that address social issues and children's mental health [12].

The role of factors that can be considered as possible alleviators to the development of mental health problems should be examined. One such factor is social support, where the existence of a social network may provide ballast that will mitigate such problems. Both peer and parent support are elements of social support important for children's and adolescent's mental health. Whereas peer support represents an external network, parent support reflects family structure and the

*Corresponding author: Dr. Berit Sofie Karlsen, Department of Landscape Architecture and Spatial Planning, Norwegian University of Life Sciences. P.O.Box.5003, No-1432 Aas, Norway, E-mail: beritsnilsen@hotmail.com

Received May 02, 2014; Accepted June 23, 2014; Published July 03, 2014

Citation: Karlsen BS, Clench-Aas J, Roy BV, Raanaas RK (2014) Relationships between Social Anxiety and Mental Health Problems in Early Adolescents from Different Socioeconomic Groups: Results from a Cross-sectional Health Survey in Norway. J Psychol Abnorm Child 3: 120. doi:10.4172/2329-9525.1000120

Copyright: (c 2014 Karlsen BS, et al. This is an open-access article distributed under the terms of the Creative Commons Attribution License, which permits unrestricted use, distribution, and reproduction in any medium, provided the original author and source are credited. 
Citation: Karlsen BS, Clench-Aas J, Roy BV, Raanaas RK (2014) Relationships between Social Anxiety and Mental Health Problems in Early Adolescents from Different Socioeconomic Groups: Results from a Cross-sectional Health Survey in Norway. J Psychol Abnorm Child 3: 120. doi:10.4172/2329-9525.1000120

Page 2 of 10

role of the adolescent within this structure [19-21]. In several studies parental role and family structure is mentioned as essential factors for depressive and affective conditions as well as Social Anxiety Disorder [6,22-24]. In children, psychosocial risk factors for the onset of mental distress include parameters often associated with lower SES, such as poor parent-child relationships and parental depression, in addition to economic adversity $[15,24]$.

Another important factor that can reduce the negative impact of mental health problems, especially in children, is the availability and use of health services. Health services with special emphasis on children and adolescents can at an early stage of disease development, help children and their families to cope with the disease.

Different patterns of health service utilization are also seen in different socioeconomic groups. Previous research indicates that a higher educational level increases access and use of specialists, whereas lower education is associated with greater use of public health services $[25,26]$.

Although social anxiety has been examined in relation to mental health problems in some studies, no other studies have elucidated a socioeconomic impact for these issues. Therefore, the aim of this study was to examine the association between social anxiety and mental health in early adolescents, related to parental socioeconomic status. We wanted to examine whether the patterns of social anxiety differed between two socioeconomic groups. Further, we wanted to investigate if possible SES differences in the relation between social anxiety disorder and mental health was mediated by social support and/ or the use of health services.

\section{Materials and Methods}

\section{Participants and procedure}

Data are derived from a cross-sectional Norwegian health profile study, performed in Akershus County (comprising 22 municipalities) in 2002 [27]. In the Health Profile survey more than 36,000 school children and their parents participated, from the third grade of primary school to the final year of high school. The aim of the original survey was to provide information about physical and mental health, wellbeing and lifestyle for this group, in a rapidly growing area near the capital of Norway.

The survey invited school classes as a whole, with a random selection for each grade level, obtaining a representative sample for each of the 22 municipalities. The children completed the questionnaire during regular lessons at school, under the supervision of a trained teacher, while parents responded to the survey at home.

Participation in the study was anonymous and voluntary. Parents and children were assigned the same registration number in the questionnaire, making it possible to compare them without violating anonymity. Parental consent was attained. Approval was provided by the Regional committee for medical research ethics.

Due to the choice of variables, the present study was limited to children and their parents from fifth to seventh grade in primary school. A total of 9707 children and 8603 parents responded the questionnaire, representing a response rate of $86.2 \%$ for children and $78 \%$ for parents.

\section{Measures}

Socioeconomic status: Parental educational level was used as an indicator of socioeconomic status. The parental questionnaire provided information on attained educational level for each parent in four categories having finished at least: elementary school (7 years), middle or junior high school (10 years), high school (13 years), and college/ university (16 years or more).

Since there were few parents with only elementary or middle and junior high school $(<15 \%)$, the educational variable was dichotomized, and recoded to low SES versus high SES. The lower educated group comprised parents having only finished elementary, middle or junior high school or high school. The highly educated group included parents who achieved an educational level consistent with college or college/ university. A new variable was created based on the family educational level: Lower SES included those families with both parents with lower educational level, and high SES includes those families with at least one parent with higher education. In single parent families, the measure represents high or low educational level of the single parent.

Mental health measured by strengths and difficulties questionnaire: Mental health problems were measured by the Strengths and Difficulties Questionnaire (SDQ), developed by Goodman [28]. In this study, the self-reported data from the children's questionnaire were used. The SDQ symptom scale contains 25 items, including five subscales covering emotional, conduct, hyperactivity and peer problems, in addition to pro-social behavior. Each sub-scale consists of five items. In the current study the pro-social scale was not included. The responses use a three-point Likert scale format that can be answered with: "not true", "somewhat true" or "certainly true". For all items, the response can be positive (rating score 2-0) or negatively worded (rating score $0-2$ ). A total symptom score represents the sum of the emotional, conduct, hyperactivity and peer problems sub-scales.

The impact supplement of SDQ [29] asks if the respondent perceives problems considering emotions, concentration, behavior and relationships with other people. If so, the respondent inquires further about chronicity, overall distress and social impairment related to family, friends, learning situation, leisure activities and lastly about burden to those people near to you. The impact questions have four response categories (no, little, quite a lot, a great deal) which corresponds to a point scale 0-0-1-2. The items concerning overall distress and social impairment generate an impact score, ranging between 0 and 10 . A total impact score of 2 or more is defined as abnormal, whereas a score of 1 as borderline.

The Norwegian version of SDQ was used. In order to comply with Goodman's recommendation of an $80-10-10 \%$ distribution of normal/ borderline and abnormal cases, it was necessary to use the Norwegian cut-offs suggested by Van Roy [30]. The SDQ total symptom score, and sub-scale scores are dichotomized using thresholds that result in a distribution equivalent to $80 \%$ for normal and $20 \%$ for those that scored borderline/abnormal.

According to previous research, internal reliability of the SDQ scale is satisfying. Goodman [31] reports the Cronbach's alpha for SDQ total symptom scale as 0.8 . In this sample, Cronbach's alpha for SDQ total scale [20 items] is 0.74 . Consistency of the SDQ impact scale gives a Cronbach's alpha of 0.68 . For variables containing a smaller amount of items, values above 0.6 are considered as acceptable [32].

\section{Social anxiety}

The parental questionnaire included a section for Social Anxiety, based on the development and well-being assessment covering DSMIV criteria A - D for Social Anxiety Disorder [33,34]. This contains a general question about extreme shyness and fear of social situations (see Table 4 for wording of questions). If the parents confirm this, the 
Citation: Karlsen BS, Clench-Aas J, Roy BV, Raanaas RK (2014) Relationships between Social Anxiety and Mental Health Problems in Early Adolescents from Different Socioeconomic Groups: Results from a Cross-sectional Health Survey in Norway. J Psychol Abnorm Child 3: 120. doi:10.4172/2329-9525.1000120

Page 3 of 10

next part of the questionnaire specifies anxiety in several situations like "meeting new people", "eating with others", "speaking in class", "reading for others" or "writing in front of others". Further questions ask: (1) whether anxiety is associated with adults or children (or both) (2), if the anxiety is caused by a fear of being embarrassed in those situations, and (3) if the child is able to get on well enough with the adults and children s/he knows best outside these situations. The final part asks if the children becomes (disturbed/show signs of anxiety) upset or avoid these situations if he or she has to deal with the feared situation. All questions could be answered with "yes" or "no".

A question on impairment (DSM-IV, criteria E) was omitted. Due to this, we do not use the term social anxiety disorder for this study. Children whose parents confirmed all five sub-items in addition to the main question, were labeled as having significant social anxiety (SSA). We assume that this group also included children with social anxiety disorder (SAD). The children whose parents answered "no" in the main question were defined as non-SA (normal). Parents who answered "yes" initially, and confirmed none or only a few of the other problem areas, seem to represent an unclear borderline group. We assume that this group also includes children with shyness, but without severe impairment in social situations. These children were defined as unspecified social anxiety (U-SA), included in the study due to the number of respondents) (Table 1). Internal reliability for the social anxiety scale used in the survey, expressed by Cronbach's alpha was measured to be 0.77 .

\section{Mediating variables}

Peer support was measured by the question: "Have at least one good friend", and answered by the early adolescents. Response options for these questions were "yes" or "no".

For measuring parental support, early adolescents were asked if "somebody at home cares about what I do". The response options for this question "yes", "a little", "not at all" and "don't know". This variable was dichotomized such that early adolescents who answered "yes", were classified as having good support at home, meanwhile early adolescents who responded to the other response alternatives were classified as not having good support at home.

Use of health services was measured with two items from the parental questionnaire: "use of educational psychological health services" and "use of psychiatrist/ psychologist", both confirmed with "yes" or "no". The distribution of these variables is given in Table 1.

\begin{tabular}{|c|c|c|c|c|c|}
\hline \multirow{3}{*}{ Characteristics } & & \multicolumn{4}{|c|}{ Parental SES } \\
\hline & & \multicolumn{2}{|c|}{ Low } & \multicolumn{2}{|c|}{ High } \\
\hline & & $\mathbf{N}$ & $\%$ & $\mathbf{N}$ & $\%$ \\
\hline \multirow[t]{3}{*}{ Social anxiety (SA) } & Non-SA & 3576 & 90.3 & 3972 & 93.2 \\
\hline & U-SA & 276 & 7.0 & 198 & 4.6 \\
\hline & SSA & 110 & 2.8 & 90 & 2.1 \\
\hline \multirow{2}{*}{ SDQ total symptom } & Normal & 3224 & 82.1 & 3730 & 88.3 \\
\hline & Borderline/ Abnormal & 705 & 17.9 & 493 & 11.7 \\
\hline \multirow{2}{*}{ SDQ impact } & Normal & 3329 & 86.1 & 3689 & 88.6 \\
\hline & Borderline/ Abnormal & 537 & 13.9 & 474 & 11.4 \\
\hline \multirow{2}{*}{ SDQ emotion } & Normal & 3112 & 79.1 & 3582 & 84.8 \\
\hline & Borderline/ Abnormal & 822 & 20.9 & 644 & 15.2 \\
\hline \multirow{2}{*}{ SDQ conduct } & Normal & 3283 & 83.5 & 3694 & 87.3 \\
\hline & Borderline/ Abnormal & 651 & 16.5 & 535 & 12.7 \\
\hline \multirow{2}{*}{ SDQ hyperactivity } & Normal & 3148 & 80.1 & 3611 & 85.4 \\
\hline & Borderline/ Abnormal & 784 & 19.9 & 615 & 14.6 \\
\hline \multirow{2}{*}{ SDQ peer problem } & Normal & 3114 & 79.2 & 3621 & 85.6 \\
\hline & Borderline/ Abnormal & 818 & 20.8 & 607 & 14.4 \\
\hline \multirow{2}{*}{ SDQ prosocial } & Normal & 3473 & 88.1 & 3792 & 89.7 \\
\hline & Borderline/ Abnormal & 467 & 11.9 & 436 & 10.3 \\
\hline \multirow{2}{*}{ Gender } & Boy & 2077 & 50.3 & 2200 & 50.1 \\
\hline & Girl & 2049 & 49.7 & 2194 & 49.9 \\
\hline \multirow{6}{*}{ Age } & 9 & 2 & 0.1 & 0 & 0.0 \\
\hline & 10 & 657 & 16.7 & 763 & 18.1 \\
\hline & 11 & 1300 & 33.0 & 1377 & 32.6 \\
\hline & 12 & 1326 & 33.7 & 1448 & 34.3 \\
\hline & 13 & 642 & 16.3 & 632 & 15.0 \\
\hline & 14 & 7 & 0.2 & 2 & 0.0 \\
\hline \multirow{2}{*}{ Peer support } & No & 257 & 6.6 & 211 & 5.0 \\
\hline & Yes & 3655 & 93.4 & 4002 & 95.0 \\
\hline \multirow{2}{*}{ Parent support } & No/ little/ don`t know & 1007 & 25.5 & 781 & 18.4 \\
\hline & Yes & 2942 & 74.5 & 3453 & 81.6 \\
\hline \multirow{2}{*}{$\begin{array}{l}\text { Educational Psychological } \\
\text { Services }\end{array}$} & No & 3714 & 89.8 & 4161 & 94.5 \\
\hline & Yes & 420 & 10.2 & 240 & 5.5 \\
\hline \multirow{2}{*}{$\begin{array}{l}\text { Psychologist/ } \\
\text { Psychiatrist }\end{array}$} & No & 4002 & 96.8 & 4291 & 97.5 \\
\hline & Yes & 132 & 3.2 & 110 & 2.5 \\
\hline
\end{tabular}

Table 1: Prevalence of different characteristics by study population, according to parent SES. 
Citation: Karlsen BS, Clench-Aas J, Roy BV, Raanaas RK (2014) Relationships between Social Anxiety and Mental Health Problems in Early Adolescents from Different Socioeconomic Groups: Results from a Cross-sectional Health Survey in Norway. J Psychol Abnorm Child 3: 120. doi: $10.4172 / 2329-9525.1000120$

Page 4 of 10

\section{Statistical analysis}

All statistical analysis was conducted using the SPSS version 20.0 software package. Statistical level was set at $\mathrm{p}<0.05$, or stricter.

Preliminary analyses included Pearson correlation coefficients between the dependent and independent main variables. Additionally ANOVA was performed to test for differences in the primary variables between parental SES.

The models were tested using hierarchal multiple logistic regression. Investigated models were performed for each of the parental SES groups, testing for significant differences in Beta and Odds Ratio. In the hierarchy, gender and age were controlled for in the first step. Step two included the social anxiety variable, and finally in step three the mediators (peer support, parental support, educational psychological service and use of psychologist/psychiatrist) were entered individually, one by one.

Dependent variables were: The SDQ total symptom score, the SDQ impact score and the four sub-scales of emotional, conduct, hyperactivity and peer problems.

To test for significant differences between the observed OR with confidence intervals (CI) for each of the SA groups and each of the SES groups, the method described by Wolfe and Hanley [35] was used. Differences between the estimates were tested independently of their significance level. The method for testing for mediation was twofold. A comparison and test for significant decline of the OR of the social anxiety variable in the hierarchal logistic regression, before and after inclusion of the mediator, was done using the methods described by Baron and Kenny and Kim et al. [36,37] with significance testing using the procedure described by Wolfe and Hanley [35]. Additionally, the Sobel test [38] was performed for all tests to determine whether the mediator pathway is significant, and thus partially accounts for the relationship between the independent and the dependent variable, thus explaining in part the direct relationship of the independent variable.

For multicollinearity testing, the tolerance values are all above 0.858 , and variance inflation factor below 1.165 for all items applied in analysis, far from violating the multicollinearity assumption [32].

\section{Results}

Among the (8152) children who responded to the Strengths and Difficulties Questionnaire in the target group for this analysis, 1204 (14.7\%) participants reported symptoms consistent with borderline or abnormal SDQ score and 1016 (12.6\%) children indicated that these symptoms had an impact on daily activities.

The prevalence of significant social anxiety (SSA), according to parent reports, was 201 children (2.4\%), while 479 children (5.8\%) were indicative of having unspecified social anxiety (U-SA).

Table 1 provides prevalence and characteristics for mental health problems and levels of social anxiety, divided in the two main groups of parental educational level (SES) (both low and at least one highly educated). The general pattern seems to indicate an increased likelihood of mental health problems in the lower SES group.

The table also shows an even distribution of age and gender between SES groups. Whereas peer support is high in both SES groups, parental support seems to be lower in the group with lower SES. The use of specialists such as psychologists or psychiatrists, are quite small in both groups. Somewhat larger numbers of children within the lowest SES group use educational psychological services.

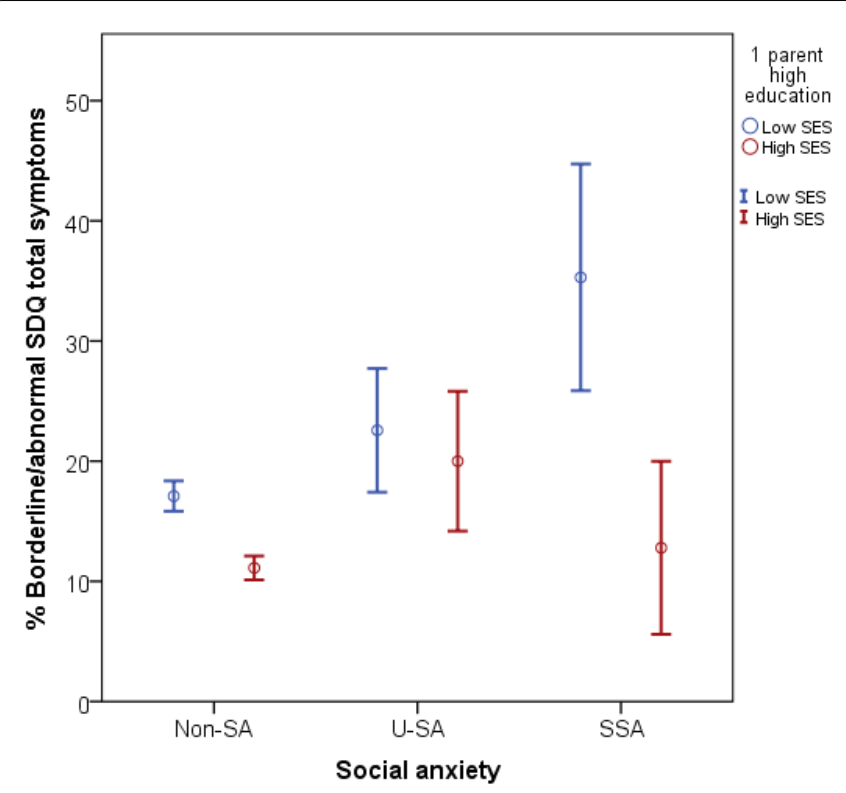

Figure 1: \% scoring borderline/abnormal in the SDQ total symptom scores for different categories of social anxiety, according to parental SES.

Figure 1, shows the percentage of children having normal or borderline/abnormal SDQ (total symptom scores) for each of the three categories of social anxiety, and for each SES group. There are significant differences in borderline/abnormal SDQ total scores between the lower and higher SES groups for the SSA and non-SA categories. No significant differences were measured in the U-SA group.

Pearson correlation coefficients were measured between the dependent variables and between the dependent variables and the social anxiety variables. The correlations between SA and the SDQ variables in the high SES group are low [ranging from 0.005 for conduct to 0.027 for emotion], also between the individual sub-scales (range from 0.120 to 0.258 ) (data not shown). In the low SES group, the correlation between SA and SDQ sub-scales are also low although higher than for the high SES group (range from 0.021 to 0.087 ) whereas between sub-scales, the correlations were similar (ranging from 0.083 to 0.255 ). Only the correlation between total symptom scores and the sub-scales are substantial, but that is to be expected as the total score is a sum of the four sub-scales. Additionally, the Pearson correlation values for the other independent variables were consistently minimal, except for the use of health services (two fairly equal services), where a correlation of 0.35 was noted (data not shown).

ANOVA was performed to measure differences between the educational groups for total symptom scores, impact, each of the four SDQ sub-scales and SA category. Differences between the SES groups were significant at the 0.001 level for all parameters. Figure 2 shows the estimated marginal means of the total symptom score for both SES groups and for each of the SA groups as measured using ANOVA. There are markedly higher levels of SDQ symptom scores for the low SES group for all three SA groups. There are equally marked differences between the U-SA and SSA groups as opposed to the non-SA group for scores associated with low SES (Figure 2).

Table 2 presents the relationship between mental health problems, measured as SDQ total symptom scores, and different categories of social anxiety for each of the two SES groups as measured by multiple logistic regression. In the group representing low SES, there was a small, 
Citation: Karlsen BS, Clench-Aas J, Roy BV, Raanaas RK (2014) Relationships between Social Anxiety and Mental Health Problems in Early Adolescents from Different Socioeconomic Groups: Results from a Cross-sectional Health Survey in Norway. J Psychol Abnorm Child 3: 120. doi:10.4172/2329-9525.1000120

Page 5 of 10

\begin{tabular}{|c|c|c|c|c|c|c|c|c|c|}
\hline & & \multicolumn{2}{|c|}{ SDQ: Total symptoms } & \multirow{2}{*}{$\begin{array}{c}\text { SA } \\
P\end{array}$} & \multirow{2}{*}{$\begin{array}{c}\text { SES } \\
P\end{array}$} & \multicolumn{2}{|c|}{ SDQ: Impact score } & \multirow{2}{*}{$\begin{array}{c}\text { SA } \\
P\end{array}$} & \multirow{2}{*}{$\begin{array}{c}\text { SES } \\
\mathbf{P}\end{array}$} \\
\hline & & $B^{b, c}$ & OR (95\%Cl) & & & B & OR $(95 \% \mathrm{Cl})$ & & \\
\hline \multirow{3}{*}{ Low SES } & $U-S A^{e}$ & $0.331^{*}$ & $1.393(1.023-1.896)$ & 0.05 & NS & 0.119 & $1.126(0.786-1.613)$ & NS & NS \\
\hline & $S S A$ & $0.958^{\star \star *}$ & $2.607(1.710-3.973)$ & & 0.05 & 0.492 & $1.636(0.979-2.734)$ & & NS \\
\hline & & & $(\mathrm{N}=3730)$ & & & & $(\mathrm{N}=3671)$ & & \\
\hline \multirow[b]{3}{*}{ SES $^{d}$} & $U-S A$ & $0.706^{\star * *}$ & $2.026(1.393-2.948)$ & NS & & 0.299 & $1.349(0.879-2.070)$ & NS & \\
\hline & $S S A$ & 0.156 & $1.169(0.616-2.221)$ & & & 0.352 & $1.422(0.781-2.589)$ & & \\
\hline & & & $(\mathrm{N}=4064)$ & & & & $(\mathrm{N}=4010)$ & & \\
\hline
\end{tabular}

aSDQ score: Strengths and difficulties questionnaire (Goodman, 2000) Norwegian cut-off points.

bNote: *P $<0.05^{* *} \mathrm{P}<0.01{ }^{* * *} \mathrm{P}<0.001$.

${ }^{c}$ Analysis is controlled for gender and age.

dParental SES: High: At least one parent having completed college/university or more; or, Low: Both having completed less.

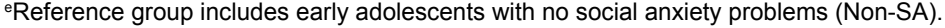

Table 2: Odds ratio $(\mathrm{OR})$ and beta $(\mathrm{B})$ resulting from logistic regression analysis examining associations of social anxiety (U-SA and SSA) and mental health (SDQ total symptom and impact score), related to parental SES.

\begin{tabular}{|c|c|c|c|c|c|}
\hline & & Emotion $^{a}$ & Conduct & Hyperactivity & Peer Problems \\
\hline & & $\begin{array}{c}\text { OR } \\
(95 \% \mathrm{Cl})^{\mathrm{b}, \mathrm{c}}\end{array}$ & OR $(95 \% \mathrm{Cl})$ & OR $(95 \% \mathrm{Cl})$ & OR $(95 \% \mathrm{Cl})$ \\
\hline \multirow{4}{*}{ Low SES ${ }^{d}$} & $U-S A^{e}$ & $1.726(1.299-2.294)^{\star * \star}$ & $0.839(0.581-1.210)$ & $1.039(0.755-1.430)$ & $1.602(1.202-2.136)^{* * *}$ \\
\hline & SSA & $2.925(1.937-2.294)^{\star * *}$ & $1.429(0.879-2.323)$ & $1.540(0.981-2.417)$ & $2.590(1.713-3.914)^{* * *}$ \\
\hline & $N$ & 3735 & 3735 & 3733 & 3733 \\
\hline & $\begin{array}{c}\text { Significance between SA } \\
\text { groups }\end{array}$ & $P<0.001$ & NS & NS & NS \\
\hline \multirow{3}{*}{ High } & U-SA & $2.158(1.529-3.045)^{\star * *}$ & $1.342(0.888-2.026)$ & $0.930(0.604-1.433)$ & $1.958(1.373-2.794)^{* * *}$ \\
\hline & SSA & $1.631(0.967-2.754)$ & $1.172(0.629-2.184)$ & $0.772(0.396-1.504)$ & $1.323(0.750-2.333)$ \\
\hline & $N$ & 4067 & 4069 & 4067 & 4068 \\
\hline SES & $\begin{array}{c}\text { Significance between SA } \\
\text { groups }\end{array}$ & NS & NS & NS & NS \\
\hline \multirow{2}{*}{$\begin{array}{l}\text { Significance between } \\
\text { SES groups }\end{array}$} & U-SA & NS & NS & NS & NS \\
\hline & SSA & $P<0.01$ & NS & NS & NS \\
\hline
\end{tabular}

aSDQ score: Strengths and difficulties questionnaire (Goodman, 2000) Norwegian cut-off points.

bNote: *P $<0.05^{* *} \mathrm{P}<0.01{ }^{* * *} \mathrm{P}<0.001$.

${ }^{\mathrm{C}}$ Analysis is controlled for gender and age.

dParental SES: High: At least one parent having completed college/university or more; or, Low: Both having completed less.

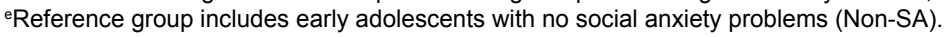

fSignificance testing according to method of Wolfe and Hanley.

Table 3: Odds ratio (OR) resulting from logistic regression analysis examining associations of social anxiety (U-SA and SSA) and mental health (SDQ subscores: emotion, conduct, hyperactivity and peer problems), related to parental SES.

but significant association between mental problems and U-SA. For the children categorized as having SSA, we measured a strong association with mental health problems.

In the group whose parents were of high SES, there was a significant association with mental health problems in the U-SA group, whereas there was no association between mental health problems and SSA for this SES group. There was a significant difference between the groups with U-SA and SSA in the low SES group but not the high SES group. There was a significant difference between the SES groups for those with SSA.

When SDQ impact score was used as a measure for mental health outcome, no significant associations between social anxiety and mental health outcome were present at any SES level. There were no significant differences between the SA groups either in the low or high SES group(s), and there were no significant differences between the SES groups for either the U-SA or the SSA groups.

Table 3 presents the results of logistic regression for each of the four sub-scales of SDQ and for each of the parental SES groups. For the low SES group, there are significant associations between both social anxiety groups and emotional and peer problems. For the high SES group these were seen only for the U- SA group. Conduct and hyperactivity problems were not significantly associated for any group. There were significant differences between SA groups only for emotional problems and only for the low SES group. There were significant differences between the SES groups only for emotional problems and only for those with SSA.

Figure 3 shows the percentage with borderline or abnormal scores for each of the sub scales for each SES group. There is a marked and significant rise in levels of emotional and peer problems for the low SES group, whereas there are no such differences for the conduct and hyperactivity problems or for the high SES group.

Table 4 presents the prevalence of responses to each of the questions used to determine social anxiety problems compared by parental SES (low/high). For this analysis we used Pearson's chi-square to evaluate if measured differences are significant between the SES groups. The introducing question (Q1) asks if the child fears or avoids social situations involving a lot of people, new people or performance in front of others. We discovered a significant difference between the groups 
Citation: Karlsen BS, Clench-Aas J, Roy BV, Raanaas RK (2014) Relationships between Social Anxiety and Mental Health Problems in Early Adolescents from Different Socioeconomic Groups: Results from a Cross-sectional Health Survey in Norway. J Psychol Abnorm Child 3: 120. doi:10.4172/2329-9525.1000120

Page 6 of 10
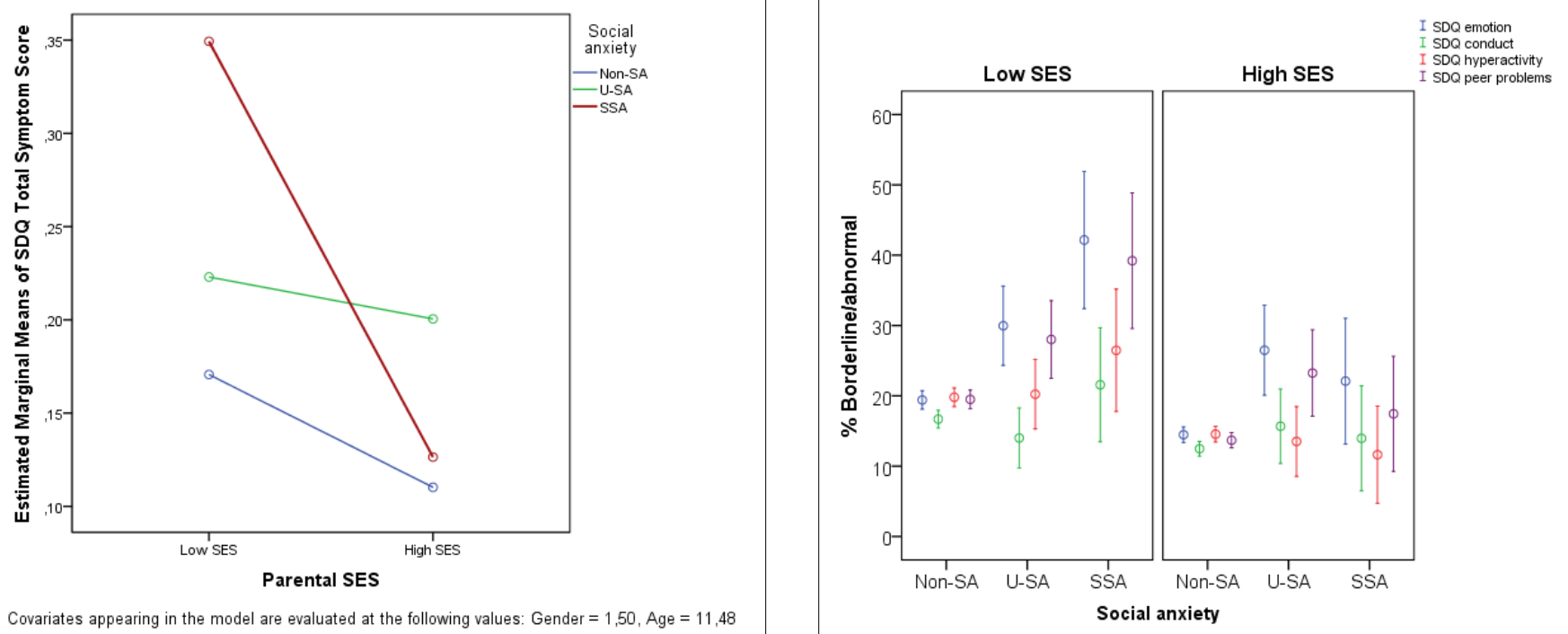

Figure 2: Estimated marginal means of the SDQ total symptom scores for different categories of social anxiety disorder, according to parental SES. Results of ANOVA. N=7794.

Figure 3: \% scoring borderline/abnormal in the SDQ sub-scores for different categories of social anxiety, according to parental SES.

\begin{tabular}{|c|c|c|c|c|c|}
\hline & $\begin{array}{l}\text { Social anxiety disorder } \\
\text { Questionnaire }\end{array}$ & $\begin{array}{l}\text { Response } \\
\text { categories }\end{array}$ & $\begin{array}{c}\text { Low SES } \\
\%\end{array}$ & $\begin{array}{l}\text { High SES } \\
\%\end{array}$ & $p$ \\
\hline Q1 & Is your child particularly afraid of, or avoids social situations? & $\begin{array}{l}\text { Yes } \\
\text { No }\end{array}$ & $\begin{array}{l}12.3 \\
87.7\end{array}$ & $\begin{array}{l}8.6 \\
91.4\end{array}$ & 0.000 \\
\hline Q2 & Has your child been particularly afraid of meeting new people over the last 4 weeks? & $\begin{array}{l}\text { Yes } \\
\text { No }\end{array}$ & $\begin{array}{l}4.3 \\
95.7\end{array}$ & $\begin{array}{l}4.1 \\
95.9\end{array}$ & $\mathrm{NS}^{\mathrm{a}}$ \\
\hline Q3 & $\begin{array}{l}\text { Has your child been particularly afraid of } \\
\text { eating in front of others over the last } 4 \text { weeks? }\end{array}$ & $\begin{array}{l}\text { Yes } \\
\text { No }\end{array}$ & $\begin{array}{l}2.3 \\
97.7\end{array}$ & $\begin{array}{l}1.0 \\
99.0\end{array}$ & 0.000 \\
\hline Q4 & $\begin{array}{l}\text { Has your child been particularly afraid of } \\
\text { speaking in class over the last } 4 \text { weeks? }\end{array}$ & $\begin{array}{l}\text { Yes } \\
\text { No }\end{array}$ & $\begin{array}{l}13.7 \\
86.3\end{array}$ & $\begin{array}{l}9.5 \\
90.5\end{array}$ & 0.000 \\
\hline Q5 & $\begin{array}{l}\text { Has your child been particularly afraid of reading out loud in front of others over the last } 4 \\
\text { weeks? }\end{array}$ & $\begin{array}{l}\text { Yes } \\
\text { No }\end{array}$ & $\begin{array}{r}18.5 \\
81.5\end{array}$ & $\begin{array}{l}10.6 \\
89.4\end{array}$ & 0.000 \\
\hline Q6 & Has your child been particularly afraid of writing in front of others over the last 4 weeks? & $\begin{array}{l}\text { Yes } \\
\text { No }\end{array}$ & $\begin{array}{r}7.0 \\
93\end{array}$ & $\begin{array}{l}4.3 \\
95.7\end{array}$ & 0.000 \\
\hline Q7 & Is your child anxious only in situations involving adults? & $\begin{array}{l}\text { Yes } \\
\text { No }\end{array}$ & $\begin{array}{l}2.9 \\
97.1\end{array}$ & $\begin{array}{l}2.5 \\
97.5\end{array}$ & NS \\
\hline Q8 & Is your child only anxious in situations involving other children? & $\begin{array}{l}\text { Yes } \\
\text { No }\end{array}$ & $\begin{array}{l}4.4 \\
95.6\end{array}$ & $\begin{array}{l}4.0 \\
96.0\end{array}$ & NS \\
\hline Q9 & Is your child anxious in situations involving both adults and other children? & $\begin{array}{l}\text { Yes } \\
\text { No }\end{array}$ & $\begin{array}{l}8.2 \\
91.8\end{array}$ & $\begin{array}{l}6.6 \\
93.4\end{array}$ & 0.003 \\
\hline Q10 & $\begin{array}{l}\text { Do you think your child's dislike of social situations is because he/she is afraid of acting in } \\
\text { a way that will be embarrassing? }\end{array}$ & $\begin{array}{l}\text { Yes } \\
\text { No }\end{array}$ & $\begin{array}{l}40 \\
60\end{array}$ & $\begin{array}{l}38.3 \\
61.7\end{array}$ & NS \\
\hline Q11 & $\begin{array}{l}\text { When your child is in, or is about to come up against one of the situations feared, does hel } \\
\text { she become anxious or upset? }\end{array}$ & $\begin{array}{l}\text { Yes } \\
\text { No }\end{array}$ & $\begin{array}{l}21.2 \\
78.8\end{array}$ & $\begin{array}{l}19.1 \\
80.9\end{array}$ & 0.022 \\
\hline Q12 & Does your child try to avoid those situations? & $\begin{array}{l}\text { Yes } \\
\text { No }\end{array}$ & $\begin{array}{l}15.8 \\
84.2\end{array}$ & $\begin{array}{l}14.4 \\
85.6\end{array}$ & NS \\
\hline Q13 & Is your child able to get along well with the adults and children he/ she knows best? & $\begin{array}{l}\text { Yes } \\
\text { No }\end{array}$ & $\begin{array}{c}99.5 \\
0.5\end{array}$ & $\begin{array}{c}99.6 \\
0.4\end{array}$ & NS \\
\hline
\end{tabular}

a. NS = non-significant values

Table 4: Prevalence of individual items in the measure of social anxiety, compared by different parental SES (significance testing using Pearson's chi-square)

investigated (12.3 versus $8.6 \%)$.

The next questions (Q2-Q6) ask if the child has been particularly afraid in social and/or performing situations during the last month. This section contains 5 items. As shown in Q2 in the table, "meeting new people" is a challenge for a small group, above $4 \%$, with no significant difference between SES-groups.

The other supplementary questions for this part (Q3-Q6), addresses situations of performing in front of others. For those children in the low
SES group, there is significantly higher prevalence of positive responses in these questions.

The next questions [Q7 to Q9] are related to "anxiety of being together with adults, with other children, or anxiety of being together with both children and adults". Only anxiety towards situations involving both adults and children, Q9, indicated a significantly higher prevalence, in the low SES group.

The next items (Q11-Q12) are related to embarrassment. Although 
Citation: Karlsen BS, Clench-Aas J, Roy BV, Raanaas RK (2014) Relationships between Social Anxiety and Mental Health Problems in Early Adolescents from Different Socioeconomic Groups: Results from a Cross-sectional Health Survey in Norway. J Psychol Abnorm Child 3: 120. doi:10.4172/2329-9525.1000120

Page 7 of 10

relatively prevalent (35 to $40 \%$ ), there were no significant differences between SES groups. When children fear social and/or performance situations, approximately $20 \%$ of the parents confirmed anxiety in these situations (significantly higher in the low SES group), with 14$15 \%$ avoiding these situations (no significant differences between SES groups).

The final question (Q13) asks if their child "is able to get on well enough with the adults and children he or she knows best". For this social situation, the groups were almost equal.

Table 5 presents the association between mental health (SDQ total symptom score) and social anxiety for each parental SES group, and for each social anxiety group. The results of the Sobel test are also described. The aim of this table is to present the mediating effect of variables like social support and use of health services.

The first part of this table provides results for the analysis controlled for social support, as measured by peer support and parental support. In step one, logistic regression for mental problems (total score) and social anxiety categories, are conducted for both SES groups (controlled for gender and age). This result is also shown in Table 2. Step 2a, provides the associations of peer support and mental health (SDQ total score) in the different SES groups. In both the group representing low and high SES, there was a non-significant decline but significant Sobel test for mediating effect of peer support for U-SA. For SSA category, there were no significant declines or significant results with the Sobel test, thus indicating no mediating effect by peer support in this group. In step $2 b$, we entered the variable measuring parental support. For the low SES group, there was a non-significant decline in OR for both SA groups, but only a significant Sobel test for the U-SA group with parental support as mediator. No results were significant for parental support in the high SES group.

The second part of Table 5, introduces the use of health services measuring impact of educational psychological service (PPT-service) in step 2a, and psychologist/psychiatrist in step 2b. Both forms of health services resulted in significant Sobel test results were significant for both SA groups and for both SES groups, indicating a mediating role for use of health services.

\section{Discussion}

In this study, we examined differences in the prevalence of symptoms of social anxiety and mental health problems, related to parental socioeconomic status (SES). We also investigated if these results were mediated by social support and use of health services. Eventual differences in the pattern of symptoms to social anxiety in different SES groups were addressed by examining the prevalence of the responses to the individual social anxiety questions used in the survey.

We used self-reported data for determining children's mental health. Previous studies have indicated children's own experiences to be a good indicator of mental health problems $[39,40]$. Children are better

\begin{tabular}{|c|c|c|c|c|c|}
\hline \multicolumn{6}{|c|}{ SDQ: TOTAL SYMPTOM SCORE } \\
\hline Social support & Step1:OR(95\%Cl) $)^{\mathrm{a}, \mathrm{b}}$ & Step2a:OR(95\%Cl) & Sobel test & Step2b:OR(95\%Cl) & Sobel test \\
\hline \multicolumn{6}{|l|}{ Low SES ${ }^{c}$} \\
\hline$U-S A^{d}$ & $1.412^{*}(1.037-1.923)$ & $1.252(0.902-1.738)$ & $* * *$ & $1.327(0.971-1.815)$ & * \\
\hline SSA & $2.628^{* * *}(1.714-4.031)$ & $2.616^{* * *}(1.673-4.089)$ & NS & $2.596^{* * *}(1.692-3.983$ & NS \\
\hline Peer support $(\mathrm{N}=3694)$ & & $0.125^{\star \star \star}(0.095-0.166)$ & & & \\
\hline Parent support $(\mathrm{N}=3721)$ & & & & $0.447^{* * *}(0.374-0.534)$ & \\
\hline \multicolumn{6}{|l|}{ High SES } \\
\hline U-SA & $2.019^{* * *}(1.382-2.950)$ & $1.519 *(1.004-2.299)$ & $* * *$ & $1.947^{* * *}(1.331-2.847)$ & NS \\
\hline SSA & $1.072(0.550-2.092)$ & $1.022(0.509-2.049)$ & NS & $1.172(0.613-2.240)$ & NS \\
\hline Peer support $(\mathrm{N}=4043)$ & & $0.103^{* * *}(0.076-0.139)$ & & & \\
\hline Parent support $(\mathrm{N}=4056)$ & & & & $0.406^{\star * *}(0.328-0.503)$ & \\
\hline Health services & Step1:OR(95\%CI) & Step2a:OR(95\%Cl) & Sobel test & Step2b:OR(95\%Cl) & Sobel test \\
\hline \multicolumn{6}{|l|}{ Low SES } \\
\hline$U-S A$ & $1.392^{*}(1.023-1.895)$ & $1.318(0.965-1.801)$ & $* *$ & $1.344(0.984-1.834)$ & * \\
\hline SSA & $2.606^{* * *}(1.710-3.971)$ & $2.182^{* * *}(1.417-3.359)$ & *** & $2.328^{* * *}(1.514-3.578)$ & $* * *$ \\
\hline PPT-service $(\mathrm{N}=3729)$ & & $2.361^{* * *}(1.846-3.020)$ & & & \\
\hline Psychologist/ psychiatrist $(\mathrm{N}=3729)$ & & & & $2.914^{\star * *}(1.985-4.297)$ & \\
\hline \multicolumn{6}{|l|}{ High SES } \\
\hline$U-S A$ & $2.026^{\star \star *}(1.393-2.948)$ & $1.877^{\star * *}(1.285-2.742)$ & $* * *$ & $1.912^{\star * *}(1.309-2.792)$ & ** \\
\hline SSA & $1.169(0.616-2.221)$ & $1.033(0.540-1.978)$ & $* * *$ & $1.017(0.581-2.111)$ & * \\
\hline PPT-service(N=4064) & & $2.145^{\star * *}(1.508-3.051)$ & & & \\
\hline Psychologist/ psychiatrist(N=4064) & & & & $2.243^{\star * *}(1.367-3.681)$ & \\
\hline
\end{tabular}

${ }^{a *} \mathrm{P}<0.05{ }^{* *} \mathrm{P}<0.01{ }^{* * *} \mathrm{P}<0.001$

${ }^{\mathrm{b}}$ Analysis is controlled for gender and age. Significance testing between Step 1 and Step 2a or b according to method of Wolfe and Hanley were all non-significant.

"Parental SES: High: At least one parent having completed college/university or more; or, Low: Both parents having completed less.

${ }^{\mathrm{d} R e f e r e n c e ~ g r o u p ~ i n c l u d e s ~ e a r l y ~ a d o l e s c e n t s ~ w i t h ~ n o ~ s o c i a l ~ a n x i e t y ~ p r o b l e m s(N o n-S A) . ~}$

ePPT-service: Use of educational psychological service, provided by the public school system.

fPsychologist/psychiatrist: Use of psychologist or psychiatrist, privately or organized by the public school system.

Table 5: Odds ratio (OR) resulting from hierarchal logistic regression analysis examining mental health (SDQ total symptom score) and social anxiety separately for the different parental SES groups. Social support and use of health services, entered in final step to test for mediation. Results for two-tailed Sobel test for indirect mediation pathway for both social support and health services variables given. 
Citation: Karlsen BS, Clench-Aas J, Roy BV, Raanaas RK (2014) Relationships between Social Anxiety and Mental Health Problems in Early Adolescents from Different Socioeconomic Groups: Results from a Cross-sectional Health Survey in Norway. J Psychol Abnorm Child 3: 120. doi:10.4172/2329-9525.1000120

Page 8 of 10

informants for emotional difficulties [more closely associated with social anxiety] than their parents [40]. Social anxiety was measured by the parents. It was a deliberate choice to separate the sources of reporting mental health and social anxiety so as not to increase a possible confusion should solely parental report be used. Additionally, it has previously been documented that discrepancies between children's self-report and parental report of SDQ were partially explained by SES differences [40].

The prevalence of significant social anxiety (SSA) in this study $(2.4 \%)$ is higher than values reported for Social anxiety disorder for the same age group in comparable studies [41,42]. For both groups exhibiting U-SA and SSA, the prediction of suffering from this condition is somewhat higher in those adolescents with lower parental SES.

The consensus in the literature is that rates of anxiety disorders are greater for those in disadvantaged SES groups [43], but there is still little mention of [parental] socioeconomic status as a risk factor in Social Anxiety Disorder [SAD] [7].

Mental health problems, measured by SDQ symptom scores, were somewhat higher in the lower SES group. This tendency is seen in both internalizing and externalizing problems, and is in concordance with a previous study of Rothenberger examining the psychometric properties of the Strengths and Difficulties Questionnaire [44]. For overall distress and social impairment as measured by the SDQ impact score, there was only a small difference between the two SES groups.

Even if social anxiety seems to be related to other mental health problems, there is still a lack of evidence in this field. The association between mental health and social anxiety is not well understood. Social anxiety is suggested to be related to internalizing problems, and in this context, depression and mood disorders [7]. This was observed in the current study with a stronger association between the internalizing subscales and social anxiety in the lower SES group.

As far as we know, there are no other studies investigating the relationship between social anxiety problems and symptoms of mental health problems, related to socioeconomic affiliation in children and adolescent groups. The results of this study show that SSA has a strong relationship to other mental health problems in children with parents of a lower educational level. For this finding, the SDQ total symptom score is used. This result is noteworthy and robust, providing a considerable distinction between the socioeconomic groups investigated.

A number of studies confirm that mental health problems occur more often in disadvantaged groups $[11,12,45]$. In many highincome countries, this issue may be related to the experience of being underprivileged [12]. The subjective evaluation of SES might create differences, even if the financial burden is minimal. A previous American study of adolescents, states that poor mental health was strongly associated with the individual sense of being disadvantaged [12]. In western communities, the impact of relative poverty also seems to make a difference $[1,46]$. Related to this, higher educational level seems to convey a feeling of mastery and coping [18]. Parental SES correlates with subjective social status for adolescents in a study concerning mental health [12].

The role of SES is unclear in relation to social anxiety problems [7]. However, when examining the symptoms of SSA available in the current study, we find clear differences between the two SES groups. Whereas fears of social interactions exist in all socioeconomic groups, our study indicates that performance in front of others is more troublesome for the group representing low SES. For activities like eating, speaking in class, reading and writing in front of others this group was reported as more inhibited.
Fear of negative evaluation by others and hypersensitivity for criticism are presented as "typical" SAD problems in previous studies $[7,47]$. This is often followed by a feeling of low self-efficacy and "fear of failure", making this group less confident in performance situations [47].

In many ways, SES seems to be linked to the feeling of personal success, indicating that the feeling of mastery, self-efficacy and being in control is associated with our placement in the social structure [46]. Furthermore, performance and achievement will be linked to the feeling of control, and access to power and social resources [48].

In a literature review, Wilkinson [49] states that SES is linked to several psychosocial factors, suggesting that the experience of socioeconomic position may create differences in health outcomes. For many children, the family social situation will be inherited [50]. Loss of self-esteem, feeling foolish, inadequate or awkward is mentioned as possible links between SES and SAD [49].

Despite the strong association in SSA and total symptom scores, there were not measured significant findings for overall distress and social impairment as measured by the SDQ impact score. The prevalence table also confirms only a small distinction between SES groups in the SDQ impact score. Only a few studies have utilized the impact score in their analysis $[51,52]$. It seems to be a tendency that Scandinavian adolescents report more symptoms than youth from most other countries [30], but less impact of the problems when compared with parent-reported data. This might suggest that perceived difficulties and burden of problems may be affected by children's age [53].

We expected social support to mediate these results. Both peer and parental support are important contributors to the mental health of children and adolescents [16,54]. Parental support is important for children and adolescents with social anxiety problems $[7,55]$. In our study there was a strong relationship between mental health problems and parental support, but little discrepancy between SES groups or mediating effect provided from the parental support variable. This indicates that children's experience of parental support contributes to children`s mental health independent of parental SES.

Our findings that peer support moderates the effect of social anxiety problems are in line with previous research. Good peer relations are important contributors to self-worth and protect against negative factors $[56,57]$. Moderate mediating effects are only seen for the U-SA category, but for both SES groups.

We also find mediating effects for both the use of the educational psychological service and psychologist/psychiatrist in both low and high SES groups. This would indicate that the use of health services does in fact impede the development of mental health problems in children with social anxiety. We find that the use of psychiatrist and psychologist is elevated in the low SES group, whereas previous research suggests the opposite. A Norwegian study, conducted in 2006, points out that highly educated parents had several advantages when accessing the health service system, and more extensive use of specialists in different health service areas [58].

In the Norwegian public school, the educational psychological service (PPT- service) is available as a part of the school system. Use of a psychologist or psychiatrist is usually a result of a referral by the PPTservices, and might explain that children in the lower SES groups access these services at an earlier stage. Norway, being a welfare state, promotes equalization of income through tax incentives, and an essentially free public healthcare system. Benefits for children are even more equalized. Thus the lack of socioeconomic differences in the mediating effect of 
Citation: Karlsen BS, Clench-Aas J, Roy BV, Raanaas RK (2014) Relationships between Social Anxiety and Mental Health Problems in Early Adolescents from Different Socioeconomic Groups: Results from a Cross-sectional Health Survey in Norway. J Psychol Abnorm Child 3: 120. doi: $10.4172 / 2329-9525.1000120$

Page 9 of 10

use of health services may be a reflection of a relatively successful equalization program. The differences seen in use of services may be more a reflection of the increased mental health problems seen in the lower SES group. Therefore, care should be taken to generalize these observations to other political-economic systems.

Compared with the SSA category, we find a stronger association between total symptom scores and U-SA in the higher SES group. It is challenging to interpret these associations because the U-SA category is an inconsistent group.

\section{Strengths and Limitations}

The strength of this study is that the health profile used is based on a large sample of children and adolescents, with a high response rate for both self-report (87\%) and parent -report 78\%).The survey covers a diverse demographic area, with extensive socioeconomic and cultural variations representing elements from both urban and rural regions.

With access to a great amount of variables, the Health Profile provides a wide range of health information. Standardized measurement methods for mental health and social anxiety are also used.

The response rate is high, but parent-response in the Health Profile study is less than for the children. The opportunity for selection bias may be present. Previous research suggests that non-respondents are more likely to have lower socioeconomic status and poorer health outcomes [59]. Selective attrition might, in this case, provide an underestimation of the problems measured.

The cross-sectional study design gives prevalence for health characteristics, and provides eventual associations of importance. Due to this, no study of causality was possible.

Even if controlled for some available health services and social support, there might be confounding factors beyond the scope of this analysis.

Dichotomizing the educational variable also introduced a challenge about cut-off points for the educational level, but contributes to a better distribution of number of participants in the two groups. Additionally, because of a change in the educational system in 1994 that had a major impact in completing high school, there could be an age bias in the least educated group.

Another limitation of the study is the determination of the Social Anxiety groups, based on parental report, with no clinical validation of the data. Definition of the SSA group is clearly related to the DSM4 criteria [34], but information about impairment criteria is lacking. In addition, the U-SA group is a more unclear and inconsistent group. This makes interpretation of results more challenging.

We must be aware of using the Health profile data collected in 2002. However, we assume that social inequalities and mental health problems still exists in our community.

\section{Conclusion}

The evidence provided in this study indicates that not only do mental health problems and social anxiety occur more often in disadvantaged groups, but for those children suffering from social anxiety the mental health consequences will be larger. Since the life-long consequences of early onset mental health problems or social anxiety can be substantial, it is necessary for an increased awareness by both health and school authorities that children may be suffering from these problems. The necessity for public authorities to address these problems is even more pronounced in the lower socioeconomic groups.

\section{Acknowledgments}

This research was completed with assistance from EXTRA funds from the Norwegian Foundation for Health and Rehabilitation, and performed in co-operation with the Norwegian National Public Institute. We thank all the responding children, parents, teachers and schools of the health profile who took part in this study.

\section{References}

1. Ahnquist J, Wamala SP (2011) Economic hardships in adulthood and mental health in Sweden. The Swedish National Public Health Survey 2009. BMC Public Health 11: 788.

2. Costello EJ, Egger $\mathrm{H}$, Angold A (2005) 10-year research update review: The epidemiology of child and adolescent psychiatric disorders: I. Methods and public health burden. J Am Acad Child Adolesc Psychiatry 44: 972-86.

3. Ford T, Goodman R, Meltzer H (2003) The British Child and Adolescent Mental Health Survey 1999: the prevalence of DSM-IV disorders. J Am Acad Child Adolesc Psychiatry 42: 1203-1211.

4. Gültekin BK, Dereboy IF (2011) The prevalence of social phobia, and its impact on quality of life, academic achievement, and identity formation in university students. Turk Psikiyatri Derg 22: 150-158.

5. Furmark T (2002) Social phobia: overview of community surveys. Acta Psychiatr Scand 105: 84-93.

6. Hidalgo RB, Barnett SD, Davidson JR (2001) Social anxiety disorder in review: two decades of progress. Int J Neuropsychopharmacol 4: 279-298.

7. Brook CA, Schmidt LA (2008) Social anxiety disorder: a review of environmental risk factors. Neuropsychiatr Dis Treat 4: 123-143.

8. Lépine JP, Pélissolo A (2000) Why take social anxiety disorder seriously? Depress Anxiety 11: 87-92.

9. Stein MB, Stein DJ (2008) Social anxiety disorder. Lancet 371: 1115-1125.

10. Van Roy B, Kristensen H, Groholt B, Clench-Aas J (2009) Prevalence and characteristics of significant social anxiety in children aged 8-13 years: a Norwegian cross-sectional population study. Soc Psychiatry Psychiatr Epidemiol 44: 407-415.

11. McLaughlin KA, Breslau J, Green JG, Lakoma MD, Sampson NA, et al. (2011) Childhood socio-economic status and the onset, persistence, and severity of DSM-IV mental disorders in a US national sample. Soc Sci Med 73: 1088-1096.

12. McLaughlin KA, Costello EJ, Leblanc W, Sampson NA, Kessler RC (2012) Socioeconomic status and adolescent mental disorders. Am J Public Health 102: $1742-1750$

13. Rutter M (2003) Poverty and child mental health: natural experiments and social causation. JAMA 290: 2063-2064.

14. Seidman E, Yoshikawa H, Roberts A, Chesir-Teran D, Allen L, et al. (1998) Structural and experiential neighborhood contexts, developmental stage, and antisocial behavior among urban adolescents in poverty. Dev Psychopathol 10: 259-281.

15. Cuffe SP, McKeown RE, Addy CL, Garrison CZ (2005) Family and psychosocial risk factors in a longitudinal epidemiological study of adolescents. J Am Acad Child Adolesc Psychiatry 44: 121-129.

16. Viner RM, Ozer EM, Denny S, Marmot M, Resnick M, et al. (2012) Adolescence and the social determinants of health. Lancet 379: 1641-1652.

17. Solar O, Irwin A, Vega J (2009) Overview and framework. In: Details Oxford textbook of public health, Oxford University Press, Oxford, England, UK.

18. Arntzen A (2002) Operasjonalisation of class. Theoretical and empirical considerations. Norwegian Journal of Epidemilogy 12: 11-17.

19. Armstrong M, Birnie-Lefcovitch S, Ungar M (2005) Pathways Between Social Support, Family Well Being, Quality of Parenting, and Child Resilience: What We Know. Journal of Child and Family Studies 14: 269-281.

20. Cutrona CE, Cole V, Colangelo N, Assouline SG, Russell DW (1994) Perceived parental social support and academic achievement: an attachment theory perspective. J Pers Soc Psychol 66: 369-378.

21. Sias P, Bartoo H (2007) Friendship, Social Support, and Health. In: L'Abate L Low-Cost Approaches to Promote Physical and Mental Health. Springer New York, USA.

22. Chavira DA, Stein MB (2005) Childhood social anxiety disorder: from understanding to treatment. Child Adolesc Psychiatr Clin N Am 14: 797-818, ix. 
Citation: Karlsen BS, Clench-Aas J, Roy BV, Raanaas RK (2014) Relationships between Social Anxiety and Mental Health Problems in Early Adolescents from Different Socioeconomic Groups: Results from a Cross-sectional Health Survey in Norway. J Psychol Abnorm Child 3: 120. doi:10.4172/2329-9525.1000120

Page 10 of 10

23. Hollenstein T, Granic I, Stoolmiller M, Snyder J (2004) Rigidity in parent-child interactions and the development of externalizing and internalizing behavior in early childhood. J Abnorm Child Psychol 32: 595-607.

24. O'Connor TG, Dunn J, Jenkins JM, Pickering K, Rasbash J (2001) Family settings and children's adjustment: differential adjustment within and across families. Br J Psychiatry 179: 110-115.

25. Regidor E, Martínez D, Calle ME, Astasio P, Ortega P, et al. (2008) Socioeconomic patterns in the use of public and private health services and equity in health care. BMC Health Serv Res 8: 183

26. Van der Heyden JH, Demarest S, Tafforeau J, Van Oyen H (2003) Socioeconomic differences in the utilisation of health services in Belgium. Health Policy 65: 153-165.

27. Aina Basilier Vaage, Laila Tingvold, Edvard Hauff, Thong Van Ta, Tore WentzelLarsen (2009) Better mental health in children of Vietnamese refugees compared with their Norwegian peers - a matter of cultural difference? Child Adolesc Psychiatry Ment Health 3: 34

28. Goodman R (1997) The Strengths and Difficulties Questionnaire: a research note. J Child Psychol Psychiatry 38: 581-586.

29. Goodman R (1999) The extended version of the strengths and difficulties questionnaire as a guide to child psychiatric caseness and consequent burden. J Child Psychol Psychiatry 40: 791-799.

30. Van Roy E (2010) Mental health problems and their impact in a cross-sectional study of Norwegian children and adolescents aged $8-19$ years.

31. Goodman R (2001) Psychometric properties of the strengths and difficulties questionnaire. J Am Acad Child Adolesc Psychiatry 40: 1337-1345.

32. Pallant J (2010) SPSS survival manual: a step by step guide to data analysis using SPSS. Maidenhead: McGraw-Hill

33. Goodman R, Ford T, Richards H, Gatward R, Meltzer H (2000) The Development and Well-Being Assessment: Description and initial validation of an integrated assessment of child and adolescent psychopathology. J Child Psychol Psychiatry 41: 645-655

34. Fredrikson M, Annas P, Fischer H, Wik G (1996) Gender and age differences in the prevalence of specific fears and phobias. Behav Res Ther 34: 33-39.

35. Wolfe R, Hanley J (2002) If we're so different, why do we keep overlapping? When 1 plus 1 doesn't make 2. CMAJ 166: 65-66.

36. Baron Rm Fau - Kenny DA, Kenny DA (1986) The moderator-mediator variable distinction in social psychological research: conceptual, strategic, and statistical considerations. J Pers Soc Psychol 51: 1173-1182.

37. Kim JS, Kaye J, Wright LK (2001) Moderating and mediating effects in causa models. Issues Ment Health Nurs 22: 63-75.

38. Sobel ME (1982) Asymptotic Confidence Intervals for Indirect Effects in Structural Equation Models. Sociological Methodology 13: 290-312.

39. Goodman R, Meltzer H, Bailey V (1998) The Strengths and Difficulties Questionnaire: a pilot study on the validity of the self-report version. Europeaun child \& Adolescent Psychiatry 7: 125-130

40. Van Roy B, Groholt B, Heyerdahl S, Clench-Aas J (2010) Understanding discrepancies in parent-child reporting of emotional and behavioural problems: Effects of relational and socio-demographic factors. BMC Psychiatry 10: 56.

41. Costello EJ, Egger HL, Angold A (2005) The developmental epidemiology of anxiety disorders: phenomenology, prevalence and comorbidity. Child Adolesc Psychiatr Clin N Am 14: 631-648.

42. Heiervang E, Stormark KM, Lundervold AJ, Heimann M, Goodman R, et al (2007) Psychiatric disorders in Norwegian 8- to 10-year-olds: an epidemiologica survey of prevalence, risk factors, and service use. J Am Acad Child Adolesc Psychiatry 46: 438-447.

43. Merikangas KR (2005) Vulnerability factors for anxiety disorders in children and adolescents. Child Adolesc Psychiatr Clin N Am 14: 649-679, vii.
44. Rothenberger A, Becker A, Erhart M, Wille N, Ravens-Sieberer U (2008) Psychometric properties of the parent strengths and difficulties questionnaire in the general population of German children and adolescents: results of the BELLA study. Eur Child Adolesc Psychiatry 17: 99-105.

45. Elstad JI, Pedersen AW (2012) The Impact of Relative Poverty on Norwegian Adolescents' Subjective Health: A Causal Analysis with Propensity Score Matching. Int J Environ Res Public Health 9 : 4715-4731.

46. Elstad JI (1998) The psycho-social perspective on social inequalities in health Sociology of Health \& IIIness $20: 598-618$.

47. Lecrubier Y, Wittchen HU, Faravelli C, Bobes J, Patel A, et al. (2000) A European perspective on social anxiety disorder. Eur Psychiatry 15: 5-16.

48. Franzblau SH, Moore M (2001) Socializing efficacy: A reconstruction of selfefficacy theory within the context of inequality. Journal of Community \& Applied Social Psychology11:83-96.

49. Wilkinson RG (1999) Health, hierarchy, and social anxiety. Ann N Y Acad Sci 896: 48-63.

50. Machenbach JP (2009) Socioeconomic inequalities in high-income countries: The facts and the options. In: Oxford textbook of public health, Oxford university press, Oxford, England, UK

51. Rothenberger A, Woerner W (2004) Strengths and Difficulties Questionnaire (SDQ)--evaluations and applications. Eur Child Adolesc Psychiatry 13 Supp 2: II1-2.

52. Vostanis P, Graves A, Meltzer H, Goodman R, Jenkins R (2006) Relationship between parental psychopathology, parenting strategies and child mental health - Findings from the GB national study. Social Psychiatry and Psychiatric Epidemiology 41: 509-514.

53. Van Roy B, Grøholt B, Heyerdahl S, Clench-Aas J (2006) Self-reported strengths and difficulties in a large Norwegian population $10-19$ years. Age and gender specific results of the extended SDQ-questionnaire. Eur Child Adolesc Psychiatry 15:189-98.

54. Marmot M (2009) Social determinants and adolescent health. Int J Public Health 54 Suppl 2: 125-127.

55. Herren C, In-Albon T, Schneider S (2013) Beliefs regarding child anxiety and parenting competence in parents of children with separation anxiety disorder. $J$ Behav Ther Exp Psychiatry 44: 53-60.

56. La Greca AM, Lopez N (1998) Social anxiety among adolescents: linkages with peer relations and friendships. J Abnorm Child Psychol 26: 83-94.

57. Zarbatany L, Hartmann DP, Rankin DB (1990) The psychological functions of preadolescent peer activities. Child Dev 61: 1067-1080.

58. Finnvold JE (2009) Likt for alle?: sosiale skilnader i bruk av helsetenester. Oslo: Helsedirektoratet.

59. Howe LD, Tilling K, Galobardes B, Lawlor DA (2013) Loss to follow-up in cohort studies: bias in estimates of socioeconomic inequalities. Epidemiology 24: 1-9. 